\title{
Randomized comparison of operator radiation exposure comparing transradial and transfemoral approach for percutaneous coronary procedures: rationale and design of the minimizing adverse haemorrhagic events by TRansradial access site and systemic implementation of angioX - RAdiation Dose study (RAD-MATRIX)
}

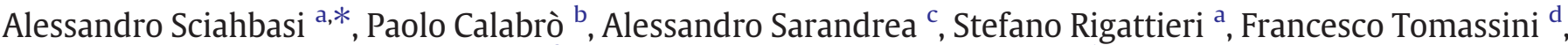 \\ Gennaro Sardella ${ }^{\mathrm{e}}$, Dennis Zavalloni ${ }^{\mathrm{f}}$, Bernardo Cortese ${ }^{\mathrm{g}}$, Ugo Limbruno ${ }^{\mathrm{h}}$, Matteo Tebaldi ${ }^{\mathrm{i}}$, \\ Andrea Gagnor ${ }^{\mathrm{d}}$, Paolo Rubartelli ${ }^{\mathrm{j}}$, Antonio Zingarelli ${ }^{\mathrm{k}}$, Marco Valgimigli ${ }^{1}$ \\ anterventional Cardiology, Sandro Pertini Hospital - ASL RMB, Rome \\ ${ }^{\mathrm{b}}$ Division of Cardiology - Department of Cardio-Thoracic Sciences - Second University of Naples \\ c HSE Management, Rome \\ d Department of Cardiology, Infermi Hospital, Rivoli \\ e La Sapienza University, Rome \\ ${ }^{\mathrm{f}}$ UO Emodinamica e Cardiologia Invasiva, IRCCS, Istituto Clinico Humanitas, Rozzano \\ ${ }^{g}$ Interventional Cardiology, Fatebenefratelli Hospital, Milan \\ h Cardiology Unit, Misericordia Hospital, Grosseto \\ i Cardiology Department, University of Ferrara; Department of Cardiology \\ j Villa Scassi Hospital, Genova \\ k San Martino Hospital, Genova \\ ${ }^{1}$ Thoraxcenter, Rotterdam
}

\section{A R T I C L E I N F O}

\section{Article history:}

Received 17 February 2014

Received in revised form 17 March 2014

Accepted 19 March 2014

\section{Keywords:}

Transradial

Radiation

Percutaneous coronary intervention

Dosimetry

\begin{abstract}
A B S T R A C T
Background: Radiation absorbed by interventional cardiologists is a frequently under-evaluated important issue. Aim is to compare radiation dose absorbed by interventional cardiologists during percutaneous coronary procedures for acute coronary syndromes comparing transradial and transfemoral access.

Methods: The randomized multicentre MATRIX (Minimizing Adverse Haemorrhagic Events by TRansradial Access Site and Systemic Implementation of angioX) trial has been designed to compare the clinical outcome of patients with acute coronary syndromes treated invasively according to the access site (transfemoral vs. transradial) and to the anticoagulant therapy (bivalirudin vs. heparin). Selected experienced interventional cardiologists involved in this study have been equipped with dedicated thermoluminescent dosimeters to evaluate the radiation dose absorbed during transfemoral or right transradial or left transradial access. For each access we evaluate the radiation dose absorbed at wrist, at thorax and at eye level. Consequently the operator is equipped with three sets (transfemoral, right transradial or left transradial access) of three different dosimeters (wrist, thorax and eye dosimeter). Primary end-point of the study is the procedural radiation dose absorbed by operators at thorax. An important secondary end-point is the procedural radiation dose absorbed by operators comparing the right or left radial approach. Patient randomization is performed according to the MATRIX protocol for the femoral or radial approach. A further randomization for the radial approach is performed to compare right and left transradial access.

Conclusions: The RAD-MATRIX study will probably consent to clarify the radiation issue for interventional cardiologist comparing transradial and transfemoral access in the setting of acute coronary syndromes.
\end{abstract}

(C) 2014 Elsevier Inc. All rights reserved.

\footnotetext{
* Corresponding author at: Interventional Cardiology, Sandro Pertini Hospital - ASL RMB, Rome, Italy. Tel.: + 3906 41433871; fax: + 390641433481.

E-mail address: alessandro.sciahbasi@fastwebnet.it (A. Sciahbasi).
}

\section{Introduction}

Interventional cardiologists are routinely and chronically exposed to ionizing radiations that are necessary to perform diagnostic and interventional coronary procedures. Moreover, some reports 
have shown that the radiation dose absorbed by interventional cardiologists is the greatest registered by any medical staff exposed to X-rays $[1,2]$.

Even if radioprotection is an important issue for operators due to the long term stochastic risk of radio-induced cancer [3], this issue is often under evaluated.

\subsection{Radiation risk for interventional cardiologists}

Generally the stochastic risk related to radiation is an all-or-none phenomenon for any individual cell, but the greater the radiation exposure, the bigger number of injured cells [4]. Other than cancerous effects, such as cataract formation, were found to be statistically related to radio-exposure [5]. In a recent study [6] an increased risk for brain and neck tumours has been observed among physicians performing interventional procedures. Consequently, operators should apply all efforts to reduce their exposition to radiation dose according to the ALARA principle [3]: operators should maintain radiation exposure at a level that is "As Low As Reasonably Achievable", limiting the duration of exposure, increasing the distance from the radiation source and implementing the shielding equipment.

Radiation dose can be expressed in different ways: the Air Kerma is the amount of energy absorbed in a given mass of air, whereas the dose area product (DAP) is the absorbed dose of radiation across a given surface area. Generally DAP measurements are more accurate than using Air Kerma measurements for the estimation of patient radiation dose as DAP allows for variations in field size [7]. DAP consents a good estimation of the dose to the irradiated tissue and is an indicator for patient cancer risk. Differently Sievert is the unit used to express the biological damage to human tissues [8] and to evaluate the radiation dose absorbed by operators.

\subsection{Transradial approach and clinical outcome}

The number of percutaneous diagnostic and interventional percutaneous coronary procedures performed through transradial approach is progressively increasing worldwide [9]. The many reasons for this "radial boom" include a reduction in vascular complications
$[10,11]$ and a better patient comfort $[12,13]$ compared to transfemoral approach. Moreover there is now a growing body of evidence that transradial approach might be associated with a better outcome in patients with acute coronary syndromes. The RIVAL [14] and the RIFLE-STEACS [15] trials are two randomized studies that showed a significant reduction in mortality with the transradial compared to transfemoral access in patients with acute ST elevation myocardial infarction. Also in non-ST elevation myocardial infarction there is a possible advantage in terms of better outcome for transradial approach even if data are conflicting. Indeed a better outcome associated with transradial approach in this subset of patients was shown in some observational studies [16] although it was not confirmed in the RIVAL study [14]. The MATRIX trial and possibly other randomized studies will clarify this issue.

\subsection{Radiation exposure according to vascular access}

Despite multiple advantages of transradial approach, a possible drawback of this access is a higher radiation exposure compared to transfemoral approach. The radiation risk might be increased both for the physician and for the patient even if data are conflicting [17-31]. Most of the studies evaluated only the radiation dose absorbed by patients and expressed it as DAP or Air Kerma (Table 1): some studies showed a significant increase in radiation dose for transradial compared to transfemoral approach, other studies showed no differences between the two approaches while in few studies a lower radiation dose for transradial approach was observed. The major bias of these studies is the observational design of the vast majority with only a few being randomized. To correct for the potential procedural biases, some authors performed a multivariate analysis [19,24,29,30], and in only one case the transradial approach was an independent predictor of increased radiation dose [29]. Another limitation of these studies is that most have assessed the fluoroscopy times, the DAP or the Air Kerma, that are only indirect measures of the radiation dose absorbed by operators. Only few studies [18,21,26,27,32] used dedicated operators' dosimeters and evaluated the radiation dose directly absorbed by operators when using different vascular accesses (Table 2). The majority of these

Table 1

Patient radiation dose in studies comparing transradial and transfemoral access

\begin{tabular}{|c|c|c|c|c|c|c|c|c|c|c|c|}
\hline Author (year) & Femoral $(n)$ & Radial ( $n$ ) & Design & Procedure & Right access (\%) & DAP femoral & DAP radial & $\mathrm{P}$ & AK femoral & AK radial & $\mathrm{P}$ \\
\hline Shah (2013) & 870 & 240 & Retr & Cor & 85 & 50.19 & 60.40 & 0.003 & 670.3 & 805.4 & 0.02 \\
\hline Shah (2013) & 512 & 74 & Retr & $\mathrm{PCI}$ & 89 & 153.95 & 196.49 & 0.02 & 2239 & 2795 & 0.03 \\
\hline Delewi (2013) & 2950 & 6614 & Prosp & Cor & NA & 31 & 31 & 0.18 & NA & NA & - \\
\hline Delewi (2013) & 2792 & 5056 & Prosp & $\mathrm{PCI}$ & NA & 79 & 73 & $<0.001$ & NA & NA & - \\
\hline Michael (2013) & 63 & 63 & Rand & Cor & 0 & NA & NA & - & $* 1080$ & $* 1290$ & 0.06 \\
\hline Michael (2013) & 30 & 24 & Rand & $\mathrm{PCI}$ & 0 & NA & NA & - & $* 1560$ & $* 1190$ & 0.18 \\
\hline Rigattieri (2013) & 243 & 1153 & Retr & Cor $+\mathrm{PCI}$ & 82 & 96.70 & 76.35 & 0.002 & NA & NA & - \\
\hline Jolly (2013) & 2255 & & Rand & Cor $+\mathrm{PCI}$ & NA & 51 & 53 & 0.828 & $† 930$ & $\dagger 1046$ & 0.051 \\
\hline Lo (2012) Senior & 25 & 25 & Prosp & Cor & 100 & $* 22.4$ & $* 21.7$ & 0.74 & NA & NA & - \\
\hline Lo (2012) Trainee & 25 & 25 & Prosp & Cor & 100 & $* 25.2$ & $* 25.4$ & 0.90 & NA & NA & - \\
\hline Hibbert (2012) & 361 & 203 & Retr & Cor $+\mathrm{PCI}$ & NA & $* 123.3$ & 194.1 & $<0.001$ & NA & NA & - \\
\hline Mercuri (2011) & 4190 & 1764 & Prosp & Cor $+\mathrm{PCI}$ & NA & NA & NA & - & 96.28 & 96.49 & $<0.001$ \\
\hline Lehmann (2010) & 842 & 624 & Prosp & Cor $+\mathrm{PCI}$ & 100 & 13.38 & 15.76 & 0.149 & NA & NA & - \\
\hline Brueck (2009) & 512 & 512 & Rand & Cor $+\mathrm{PCI}$ & NA & 38.2 & 41.9 & 0.034 & NA & NA & - \\
\hline Achenbach (2008) & 155 & 152 & Rand & Cor $+\mathrm{PCI}$ & 92 & *3.199 & $* 3.737$ & 0.13 & NA & NA & - \\
\hline Lange (2006) & 103 & 92 & Rand & Cor & 100 & $* 13.1$ & $* 15.1$ & $<0.05$ & NA & NA & - \\
\hline Lange (2006) & 48 & 54 & Rand & $\mathrm{PCI}$ & 100 & $* 51$ & $* 46.3$ & NS & NA & NA & - \\
\hline Sandborg (2004) & 40 & 36 & Prosp & Cor & NA & 33 & 45 & 0.0026 & NA & NA & - \\
\hline Sandborg (2004) & 42 & 24 & Prosp & $\mathrm{PCI}$ & NA & 40 & 69 & 0.013 & NA & NA & - \\
\hline Geijer (2004) & 114 & 55 & Posp & Cor $+\mathrm{PCI}$ & 98 & 54 & 51.9 & NS & NA & NA & - \\
\hline Larrazet (2003) & 184 & 218 & Prosp & $\mathrm{PCI}$ & NA & 175 & 138 & $<0.001$ & NA & NA & - \\
\hline
\end{tabular}

$\mathrm{DAP}\left(\mathrm{Gycm}^{2}\right)$ and $\mathrm{AK}(\mathrm{mGy})$ results are expressed as median.

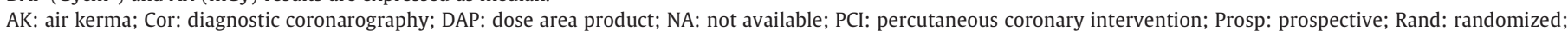
Retr: retrospective.

* Results are expressed as mean.

Data are available for 1445 patients.

${ }^{9}$ Results are expressed as mean logarithmically transformed air kerma. 
Table 2

Operator radiation dose in studies comparing transradial and transfemoral access.

\begin{tabular}{|c|c|c|c|c|c|c|c|c|c|}
\hline Author (year) & Femoral $(n)$ & Radial $(n)$ & Design & Procedure & Right access (\%) & Dose femoral & Dose radial & $\mathrm{P}$ & Site \\
\hline Michael (2013) & 63 & 63 & Rand & Cor & 0 & $13 \pm 10$ & $26 \pm 17$ & $<0.01$ & Breast pocket \\
\hline Michael (2013) & 30 & 24 & Rand & PCI & 0 & $8.1 \pm 7.1$ & $13.9 \pm 17.6$ & 0.25 & Breast pocket \\
\hline Lo (2012) Senior & 25 & 25 & Prosp & Cor & 100 & $6.1 \pm 5.6$ & $6.4 \pm 4.7$ & 0.85 & Left clavicle \\
\hline Lo (2012) Trainee & 25 & 25 & Prosp & Cor & 100 & $8.8 \pm 4.3$ & $8.5 \pm 6.5$ & 0.86 & Left clavicle \\
\hline Brasselet (2008) & 98 & 150 & Prosp & Cor & NA & *13 (1-164) & $* 29(1-195)$ & $<0.001$ & Left arm \\
\hline Brasselet (2008) & 83 & 90 & Retr & Cor + PCI & NA & $* 41(2-360)$ & *69.5 (4-531) & $<0.018$ & Left arm \\
\hline Lange (2006) & 103 & 92 & Rand & Cor & 100 & $32 \pm 39$ & $64 \pm 55$ & $<0.001$ & Breast pocket \\
\hline Lange (2006) & 48 & 54 & Rand & $\mathrm{PCI}$ & 100 & $110 \pm 115$ & $166 \pm 188$ & $<0.05$ & Breast pocket \\
\hline Sandborg (2004) & 13 & 9 & Prosp & $\mathrm{Cor}+\mathrm{PCI}$ & NA & 55 & 170 & $<0.01$ & Finger \\
\hline
\end{tabular}

Dose $n \mu \mathrm{Sv}$ ) results are expressed as mean.

Cor: diagnostic coronarography; NA: not available; $\mathrm{PCI}$ : percutaneous coronary intervention; Prosp: prospective; Rand: randomized.

* Results are expressed as median with interquartile range.

studies showed an increased operator radiation exposure with transradial compared to transfemoral access, although most data come from non randomized studies.

The main reasons for the possible higher radiation dose during transradial access are probably related to the more complicated catheter manipulation requiring prolonged fluoroscopy time and to the more unfavourable operator position, closer to X-ray source, especially for less skilled operators. These difficulties are easily overcome increasing the "radial competence" [33], but the magnitude of radiation exposure during transradial compared to transfemoral access for operators experienced in transradial approach is still unclear.

A final issue for the radiation dose in transradial approach is the "side arm effect". Most of the studies evaluating the operator and patient radiation dose during transradial and transfemoral percutaneous coronary procedures were performed using the right radial access. However in at least three previous studies [34-36], the left transradial approach compared to the right access was associated with reduced radiation dose for operators. The reason of this possible reduction in radiation dose is unknown until now even if a possible explanation might be a modest but significant reduction in fluoroscopy time [37].

At present there is only one study [18] comparing the left radial approach with the femoral access in terms of radiation dose absorbed either by the patients or by the operators. In this study a higher radiation dose for left radial compared to transfemoral approach has been observed, but this study has been performed only in patients with previous coronary artery by-pass.

\subsection{Aim and end-points of the study}

Aim of our study is to evaluate the radiation dose absorbed by operators during percutaneous coronary procedures in the setting of acute coronary syndromes comparing the transradial and the transfemoral approach. The radiation exposure during right or left transradial procedures is also compared.

The primary end-point of the study is the procedural radiation dose absorbed by operators and detected by thermo luminescent dosimeters placed at thorax level of the operators. Key secondary endpoints are the procedural radiation dose measured at the operator's wrist and eye. Other secondary end-points are the radiation dose normalized by DAP and by fluoroscopy time, fluoroscopy times and DAP values.

\subsection{Study design and population}

The MATRIX (Minimizing Adverse Haemorrhagic Events by TRansradial Access Site and Systemic Implementation of angioX) trial (NCT01433627) has been designed to compare the clinical outcome of patients with acute coronary syndromes treated invasively according to the access site (transfemoral vs. transradial) and to the anticoagulant therapy (bivalirudin vs. heparin). It is a large-scale, multicenter, prospective, open-label trial, conducted at approximately 100 sites in Europe in centers performing either transradial and transfemoral approach for percutaneous coronary procedures and will enrol more than 8,000 patients.

All diagnostic or interventional procedures performed in selected centers by operators involved in the MATRIX trial are included in this sub-study without exclusion criteria. The operator and center selection is performed according to the operator experience and to the recruiting volume: only highly experienced operators and high volume recruiting centers are included in this substudy. Moreover in the operators' selection for our sub-study, we also required that operators can perform equally right or left transradial access.

Operator radiation exposure is assessed using three sets of three dedicated dosimeters for the femoral approach, for the right radial approach and for the left radial approach.

Effective doses delivered to patients are expressed as DAP and measured in $\mathrm{Gycm}^{2}$. The DAP is directly measured by the collimator of the angiographic system. The duration of the procedure is expressed in minutes of fluoroscopy time.

\subsection{Dosimeters description}

The study uses lithium fluoride thermo luminescent dosimeters with a range of linearity from $1 \mu \mathrm{Gy}$ to $10 \mathrm{~Gy}$. All dosimeters, contained in a plastic package for water and dust risk, are easy to wear and do not interfere with operator comfort during the procedures. In order to facilitate delivery and collection of data, dosimeter's label clearly indicate operator's code, access site (femoral, right or left radial) and body destination (eye, throax or wrist) (Fig. 1). The dosimeter's design is different according to it placement:

1. Thorax dosimeter: this dosimeter consists of a case (badge) containing two thermoluminescent detectors under two filter of various materials in a symmetrical configuration, so it can be worn in each side. The thorax dosimeter is placed in the breast pocket outside the lead apron.

2. Wrist dosimeters: dosimeters for the wrist weigh less than 2 grams and can be incorporated in a waterproof flexible package and worn under surgical gloves (Fig. 1).

3. Eye dosimeter: this dosimeter contains three different filters, have a weight $<3$ grams and is placed on the head cup (Fig. 1).

According to the randomization of the MATRIX trial, operators locate the three dosimeters on the left wrist, at mid thorax level, in the breast pocket outside the lead apron and at eye level outside the lead glasses (Fig. 2). At the end of the study the dosimeters will be send to TECNORAD co. (Verona, Italy) to measure the radiation dose absorbed by operators. The radiation dose obtained for each dosimeter is then divided for the number of procedures in whom the dosimeter has been employed in order to obtain the mean radiation dose per procedure. 

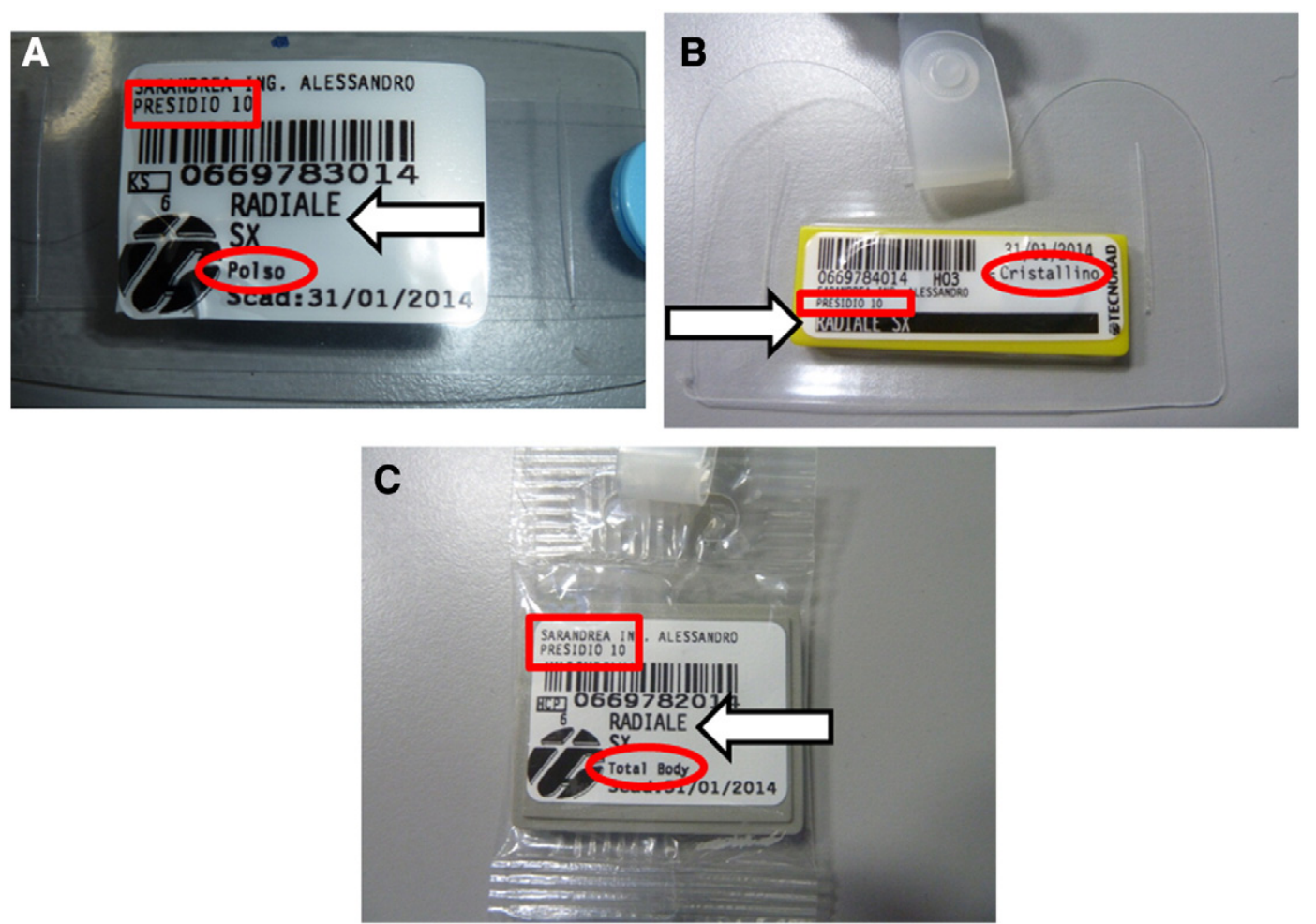

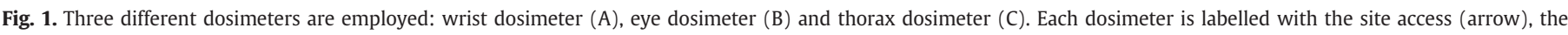
operator code (square) and with the body destination (circle).

\subsection{Randomization and statistical considerations}

Patient randomization is performed according to the MATRIX protocol for the femoral or radial approach using a Web-based system. A further randomization for the radial approach is performed

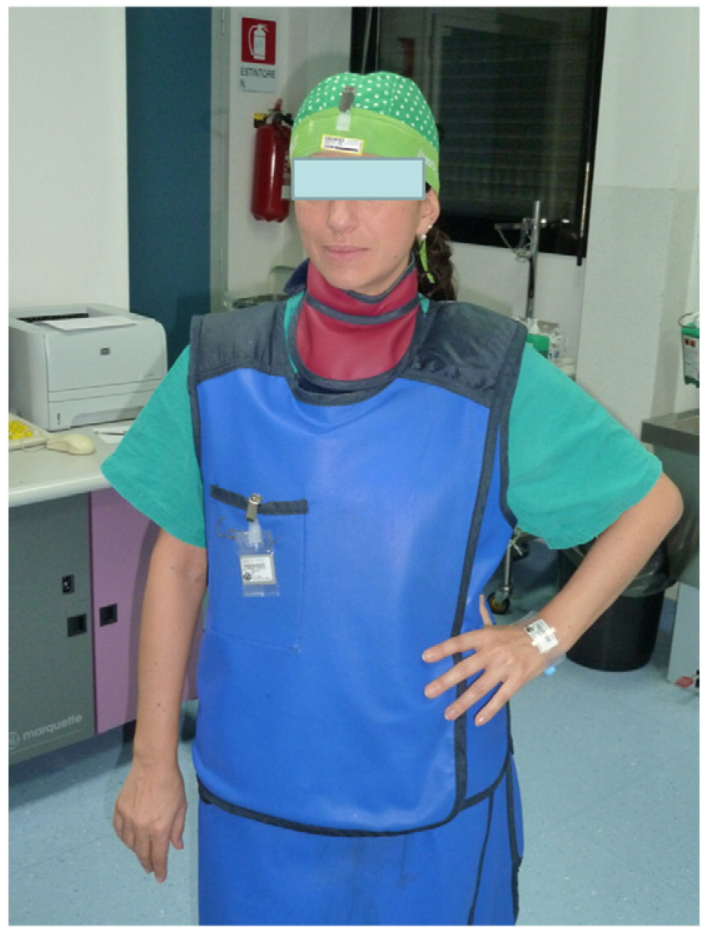

Fig. 2. Placement of the three dosimeters. The operator is equipped with three dosimeters per access: one dosimeter is placed at left wrist, another is fixed at the breast pocket and the third on the head cup close to the eye. according to the identification (ID) number of patient: odd ID numbers are assigned to right radial whereas even ID numbers are assigned to left radial access. The data analysis will be performed as "intention to treat," and consequently operators do not need to remove their dosimeters if they need to switch from transradial to transfemoral approach or vice versa. Considering that only highly experienced operators are involved in this sub-study we will expect a very low rate of cross over from one to the other vascular access.

The sample size was estimated on the basis of the primary endpoint (procedural radiation dose absorbed at thorax by operators comparing transradial vs. transfemoral approach). The primary non inferiority hypothesis of this study is that the radial approach does not cause an increase of radiation dose to the operator compared to transfemoral approach. Considering that our dosimeters measure the cumulative radiation dose, the sample size is calculated for the number of dosimeters needed rather than for the number of procedures. Moreover to avoid potential procedural biases (for example balancing long vs. short procedures), each dosimeter should be used in at least 12 procedures per access. According to a previous study evaluating the thorax operator radiation dose for transradial compared to transfemoral approach [26], showing a procedural mean dose of 142 microSievert for a single percutaneous coronary diagnostic plus interventional procedure through transfemoral approach we determined that 26 dosimeters (13 per access) would provide a power of $80 \%$ to calculate a non inferiority margin of 25 microSievert (18\% difference) with a one-sided alpha level of 0.05 . Since each set of dosimeters will be used in at least 12 patients a minimum of 312 patients will be enrolled in the present study.

\subsection{Percutaneous coronary procedure}

The coronary procedure is performed according to the MATRIX protocol and according to the standard of each operator involved in the study: the sheath selection (long vs. short, hydrophilic vs. non hydrophilic), the catheter curve employed and the use of adjunctive 
tools (manual thrombus-aspiration, intracoronary ultrasound) is left to the operator's choice.

Standard operator radio-protection in all procedures is ensured using a lead apron (two layers of $0.25 \mathrm{~mm}$ lead equating to $0.5 \mathrm{~mm}$ in the front of the operator), a thyroid lead collar, leaded glasses $(0.5 \mathrm{~mm}$ leaded-equivalent for each), under-table leaded flaps attached to the table, and an upper mobile leaded glass suspended from the ceiling.

\section{Conclusions}

Considering the controversial data on transradial and transfemoral approach in terms of radiation dose absorbed by interventional cardiologists, the RAD-MATRIX study will give more detailed information on this issue, collecting data on radiation exposure at various parts of the body.

\section{References}

[1] Venneri L, Rossi F, Botto N, Andreassi MG, Salcone N, Emad A, et al. Cancer risk from professional exposure in staff working in cardiac catheterization laboratory: insights from the National Research Council's Biological Effects of ionizing Radiation VII Report. Am Heart J 2009;157:118-24.

[2] Vañó E, González L, Guibelalde E, Fernández JM, Ten JI. Radiation exposure to medical staff in interventional and cardiac radiology. Br J Radiol 1998;71:954-60.

[3] Moores BM, Regulla D. A review of the scientific basis for radiation protection of the patient. Radiat Prot Dosimetry 2011;147:22-9.

[4] Bashore TM. Radiation safety in the cardiac catheterization laboratory. Am Heart J 2004;147:375-8.

[5] Bolus NE. Basic review of radiation biology and terminology. J Nucl Med Technol 2001;29:67-73.

[6] Roguin A, Goldstein J, Bar O, Goldstein JA. Brain and neck tumors among physicians performing interventional procedures. Am J Cardiol 2013;111:1368-72.

[7] Bor D, Sancak T, Olgar T, Elcim Y, Adanali A, Sanlidilek U, et al. Comparison of effective doses obtained from dose-area product and air kerma measurements in interventional radiology. Br J Radiol 2004;77:315-22.

[8] Park EY, Shroff AR, Crisco LVT, Vidovich MI. A review of radiation exposures associated with radial catheterization. Eurointervention 2013;9:745-53.

[9] Rao SV, Cohen MG, Kandzari DE, Bertrand OF, Gilchrist IC. The transradial approach to percutaneous coronary intervention. J Am Coll Cardiol 2010;55:2187-95.

[10] Agostoni P, Biondi-Zoccai GGL, De Benedictis ML, Rigattieri S, Turri M, Anselmi M, et al. Radial versus femoral approach for percutaneous coronary diagnostic and interventional procedures. J Am Coll Cardiol 2004;44:349-56.

[11] Jolly SS, Amlani S, Hamon M, Yusuf S, Mehta SR. Radial versus femoral access for coronary angiography or intervention and the impact on major bleeding and ischemic events: a systematic review and meta-analysis of randomized trials. Am Heart J 2009;157:132-40.

[12] Cooper CJ, El-Shiekh RA, Cohen DJ, Blaesing L, Burket MW, Basu A, et al. Effect of transradial access on quality of life and cost of cardiac catheterization: a randomised comparison. Am Heart J 1999;138:430-6.

[13] Sciahbasi A, Fischetti D, Picciolo A, Patrizi R, Sperduti I, Colonna G, et al. Transradial access compared with femoral puncture closure devices in percutaneous coronary procedures. Int J Cardiol 2009;137:199-205

[14] Mehta SR, Jolly SS, Cairns J, Niemela K, Rao SV, Cheema AN, et al. RIVAL Investigators. Effects of radial versus femoral artery access in patients with acute coronary syndromes with or without ST-segment elevation. J Am Coll Cardiol 2012;60:2490-9

[15] Romagnoli E, Biondi-Zoccai G, Sciahbasi A, Politi L, Rigattieri S, Pendenza G, et al. Radial versus femoral randomized investigation in ST-segment elevation acute coronary syndrome: the RIFLE-STEACS (Radial Versus Femoral Randomized Investigation in ST-Elevation Acute Coronary Syndrome) study. J Am Coll Cardiol 2012;60:2481-9.

[16] Sciahbasi A, Pristipino C, Ambrosio G, Sperduti I, Scabbia EV, Greco C, et al. Arterial access-site-related outcomes of patients undergoing invasive coronary procedures for acute coronary syndromes (from the ComPaRison of Early Invasive and Conservative Treatment in Patients With Non-ST-ElevatiOn Acute Coronary Syndromes [PRESTO-ACS] Vascular Substudy). Am J Cardiol 2009;103:796-800.
[17] Shah B, Bangalore S, Feit F, Fernandez G, Coppola J, Attubato MJ, et al. Radiation exposure during coronary angiography via transradial or transfemoral approaches when performed by experienced operators. Am Heart J 2013;165:286-92.

[18] Michael TT, Alomar M, Papayannis A, Mogabgab O, Patel VG, Rangan BV, et al. A randomized comparison of the transradial and transfemoral approaches for coronary artery bypass graft angiography and intervention: the RADIAL-CABG Trial (RADIAL Versus Femoral Access for Coronary Artery Bypass Graft Angiography and Intervention). JACC Cardiovasc Interv 2013;6:1138-44.

[19] Rigattieri S, Sciahbasi A, Mussino E, Drefahl S, Pugliese FR. Vascular access route (radial vs femoral) and radiation exposure in percutaneous coronary interventions and diagnostic angiography. J Invasive Cardiol 2013;25(Suppl. E):28-9 [E].

[20] Jolly SS, Cairns J, Niemela K, Steg PG, Natarajan MK, Cheema AN, et al. Effect of radial versus femoral access on radiation dose and the importance of procedural volume: a substudy of the multicenter randomized RIVAL trial. JACC CardiovasC Interv 2013;6:258-66.

[21] Lo TS, Ratib K, Chong AY, Bhatia G, Gunning M, Nolan J. Impact of access site selection and operator expertise on radiation exposure; a controlled prospective study. Am Heart J 2012;164:455-61.

[22] Hibbert B, Simard T, Wilson KR, Hawken S, Wells GA, Ramirez FD, et al. Transradial versus transfemoral artery approach for coronary angiography and percutaneous coronary intervention in the extremely obese. JACC Cardiovasc Interv 2012;5:819-26.

[23] Achenbach S, Ropers D, Kallert L, Turan N, Krähner R, Wolf T, et al. Transradial versus transfemoral approach for coronary angiography and intervention in patients above 75 years of age. Catheter Cardiovasc Interv 2008;72:629-35.

[24] Geijer H, Persliden J. Radiation exposure and patient experience during percutaneous coronary intervention using radial and femoral artery access. Eur Radiol 2004;14:1674-80.

[25] Larrazet F, Dibie A, Philippe F, Palau R, Klausz R, Laborde F. Factors influencing fluoroscopy time and dose-area product values during ad hoc one-vessel percutaneous coronary angioplasty. Br J Radiol 2003;76:473-7.

[26] Lange HW, von Boetticher H. Randomized comparison of operator radiation exposure during coronary angiography and intervention by radial or femoral approach. Catheter Cardiovasc Interv 2006;67:12-6.

[27] Sandborg M, Fransson SG, Pettersson H. Evaluation of patient absorbed doses during coronary angiography and intervention by femoral and radial artery access. Eur Radiol 2004;14:653-8.

[28] Brueck M, Bandorski D, Kramer W, Wieczorek M, Höltgen R, Tillmanns H. A randomized comparison of transradial versus transfemoral approach for coronary angiography and angioplasty. JACC Cardiovasc Interv 2009;2:1047-54.

[29] Mercuri M, Mehta S, Xie C, Valettas N, Velianou JL, Natarajan MK. Radial artery access as a predictor of increased radiation exposure during a diagnostic cardiac catheterization procedure. JACC Cardiovasc Interv 2011:4:347-52.

[30] Delewi R, Hoebers LP, Råmunddal T, Henriques JP, Angerås O, Stewart J, et al. Clinical and procedural characteristics associated with higher radiation exposure during percutaneous coronary interventions and coronary angiography. Circ Cardiovasc Interv 2013;6:501-6.

[31] Lehmann R, Ehrlich JR, Weber V, de Rosa S, Gotarda MN, Schächinger V, et al. Implementation of the transradial approach for coronary procedures is not associated with an elevated complication rate and elevated radiation patient exposure. J Interv Cardiol 2011;24:56-64.

[32] Brasselet C, Blanpain T, Tassan-Mangina S, Deschildre A, Duval S, Vitry F, et al. Comparison of operator radiation exposure with optimized radiation protection devices during coronary angiograms and ad hoc percutaneous coronary interventions by radial and femoral routes. Eur Heart J 2008;29:63-70.

[33] Sciahbasi A, Romagnoli E, Trani C, Burzotta F, Pendenza G, Tommasino A, et al. Evaluation of the "learning curve" for left and right radial approach during percutaneous coronary procedures. Am J Cardiol 2011;108:185-8.

[34] Sciahbasi A, Romagnoli E, Trani C, Burzotta F, Sarandrea A, Summaria F, et al. Operator radiation exposure during percutaneous coronary procedures through the left or right radial approach: the TALENT dosimetric substudy. Circ Cardiovasc Interv 2011;4:226-31.

[35] Pelliccia F, Trani C, Biondi-Zoccai GG, Nazzaro M, Berni A, Patti G, et al. Comparison of the feasibility and effectiveness of transradial coronary angiography via right versus left radial artery approaches (from the PREVAIL Study). Am J Cardiol 2012;110:771-5.

[36] Dominici M, Diletti R, Milici C, Bock C, Placanica A, D'Alessandro G, et al. Operator exposure to $\mathrm{X}$-ray in left and right radial access during percutaneous coronary procedures: OPERA randomised study. Heart 2013;99:480-4.

[37] De Rosa S, Torella D, Caiazzo D, Giampà S, Indolfi C. Left radial access for percutaneous coronary procedures: from neglected to performer? A metaanalysis of 14 studies including 7,603 procedures. Int J Cardiol 2014;171:66-72. 